\title{
Artikel
}

\section{Ne bis in idem revisited. Over de lotgevallen van een beginsel}

Prof. mr. J.H. Crijns en mr. dr. M.L. van Emmerik*

\section{Inleiding}

Hoewel het Tijdschrift voor Bijzonder Strafrecht E Handhaving nog relatief jong is, heeft de redactie besloten dat het eerste lustrum van dit tijdschrift een mooie aanleiding vormt om terug te blikken op een aantal ontwikkelingen op het terrein van het bijzonder strafrecht in de afgelopen vijf jaar, met daaraan gekoppeld de vraag hoe de belichte thema's zich in de nabije toekomst verder zullen ontwikkelen. In deze bijdrage pakken wij de door de redactie aangereikte handschoen graag op door de lotgevallen van het ne bis in idem-beginsel in de afgelopen jaren onder de loep te nemen, waarbij wij ons meer specifiek richten op de vraag of en in hoeverre dit beginsel in de weg staat aan de cumulatie van strafrechtelijke en punitief-bestuursrechtelijke procedures. Aanleiding om specifiek dit thema te belichten vormt het feit dat een van ons in 2015 een annotatie schreef bij het arrest van de Hoge Raad waarin de samenloop van een strafrechtelijke vervolging met een eerdere oplegging van een alcoholslotprogramma langs de weg van het bestuursrecht in strijd werd geacht met de ne bis in idemgedachte. ${ }^{1}$ Daarnaast schreven wij recent reeds een bijdrage over de samenloop tussen strafrecht en punitief bestuursrecht, waarbij de focus lag op de vraag of en op welke wijze - in geval van toegestane samenloop tussen

Prof. mr. J.H. Crijns is hoogleraar straf- en strafprocesrecht aan de Universiteit Leiden en raadsheer-plaatsvervanger in het Gerechtshof Den Haag. Mr. dr. M.L. van Emmerik is universitair hoofddocent staats- en bestuursrecht aan de Universiteit Leiden en rechter-plaatsvervanger in de Rechtbank Midden-Nederland.

1. Zie de annotatie van J.H. Crijns bij HR 3 maart 2015, ECLI:NL:HR2015: 434 (Alcoholslotprogramma) in TBS\&H 2015, nr. 4, p. 170-182. meerdere (punitieve) procedures - de evenredigheid van de sanctionering voldoende kan worden gewaarborgd. ${ }^{2}$ In de navolgende bijdrage werpen wij - gegeven de blijkens recente jurisprudentie toenemende mogelijkheden tot samenloop van punitieve procedures - de vraag op of en in hoeverre een dergelijke samenloop opportuun of doelmatig kan worden geacht. Of anders en huiselijker geformuleerd: is dergelijke cumulatie van sancties niet wat te veel van het goede? Op deze specifieke vraag gaan wij aan het slot van deze bijdrage in, zonder overigens de pretentie te hebben deze binnen het bestek van deze bijdrage ook daadwerkelijk te kunnen beantwoorden. Eerst volgt in het navolgende een schets van hetgeen de Hoge Raad in het Alcoholslotprogramma-arrest ten aanzien van de (on)mogelijkheden van dubbele sanctionering bepaalde en de ontwikkelingen van het verbod van dubbele bestraffing op hoofdlijnen sindsdien. Hierbij zal blijken dat zich met name op Europees niveau belangrijke ontwikkelingen hebben voorgedaan ten aanzien van de werking van dit verbod.

\section{Het Alcoholslotprogramma- arrest}

Zoals inmiddels bekend mag worden verondersteld, ging het in het Alcoholslotprogramma-arrest om de vraag of en in hoeverre het instellen van een strafvervolging voor rijden onder invloed nog toelaatbaar was indien voor ditzelfde feit eerder al door het CBR langs bestuursrechtelijke weg een zogenoemd alcoholslotpro-

2. Zie J.H. Crijns \& M.L. van Emmerik, 'Samenloop tussen strafrecht en punitief bestuursrecht. Zoeken naar evenredige bestraffing', NJB 2018/749. 
gramma was opgelegd. ${ }^{3}$ Zonder op deze plaats nog al te zeer op de onderliggende feiten in te gaan, ${ }^{4}$ was voor de beantwoording van deze rechtsvraag met name van belang dat deelname aan dit programma voor de verdachte ingrijpende (financiële) gevolgen had en dat een weigering tot deelname onherroepelijk de intrekking van het rijbewijs tot gevolg zou hebben, nu deze factoren bijdroegen aan het (mogelijk) punitieve karakter van het alcoholslotprogramma. $\mathrm{Na}$ onder meer uitgebreid te zijn ingegaan op het nationale en internationale juridische kader ten aanzien van het ne bis in idem-beginsel, overwoog de Hoge Raad in antwoord op voornoemde rechtsvraag als volgt:

'Tegen de achtergrond van het hiervoor overwogene is bij de huidige Nederlandse regelgeving de strafvervolging van een verdachte ter zake van het rijden onder invloed van alcoholhoudende drank in strijd met de beginselen van een goede procesorde in die gevallen waarin de verdachte op grond van datzelfde feit de onherroepelijk geworden verplichting tot deelname aan het asp is opgelegd. Die beginselen van een goede procesorde kunnen immers meebrengen - en brengen in de hier aan de orde zijnde gevallen ook mee - dat een inbreuk op het beginsel dat iemand niet twee maal kan worden vervolgd en bestraft voor het begaan van hetzelfde feit, de niet-ontvankelijkheid van het openbaar ministerie in de strafvervolging tot gevolg heeft. ${ }^{5}$

Op zichzelf was dit een alleszins begrijpelijke uitkomst van de procedure. Om tot deze uitkomst te komen moest de Hoge Raad echter wel eerst het verbod van dubbele bestraffing tot een van de beginselen van een goede procesorde 'verheffen', omdat een ander aangrijpingspunt om het verbod van dubbele bestraffing op onderhavige feitenconstellatie 'los te laten' in wezen ontbrak. In casu was immers van dubbele strafrechtelijke vervolging in de zin van artikel $68 \mathrm{Sr}$ geen sprake, terwijl artikel 243 lid $2 \mathrm{~Sv}$ en artikel 5:44 Awb evenmin van pas kwamen, nu deze enkel de (verboden) cumulatie van een strafvervolging met de oplegging van een bestuurlijke boete regarderen. Artikel 4 Zevende Protocol EVRM en artikel 50 van het EU-Grondrechtenhandvest boden in het onderhavige geval evenmin soelaas, nu Nederland het betreffende protocol niet heeft geratificeerd en in het onderhavige geval in de verste verte geen sprake was van toepassing van Unierecht.

Los van het feit dat de Hoge Raad met dit oordeel - samen met dat van de Afdeling bestuursrechtspraak van de Raad van State een dag later ${ }^{6}$ - het alcoholslotprogramma definitief de das omdeed en daarmee een einde maakte aan een jarenlange praktijk die achteraf bezien moet worden gekenschetst als dubbele bestraffing, lag het belang van deze uitspraak met name in het feit dat de Hoge Raad hiermee het verbod van dubbele bestraf- fing tot een van de beginselen van een goede procesorde 'verhief'. Daarmee is niet gezegd dat dit verbod voor die tijd zeggingskracht zou missen (anders zou het immers niet mogelijk zijn geweest de ne bis in idem-gedachte tot een van de beginselen van een goede procesorde te verheffen), maar wel dat daarmee de reikwijdte hiervan leek te worden vergroot, nu de toepassing van dit verbod - door het tot beginsel te verheffen - niet langer afhankelijk was van de precieze reikwijdte of toepasselijkheid van voornoemde bepalingen waarin het meer concreet tot uitdrukking is gebracht. Met name leek hiermee een nieuwe dageraad aangebroken voor de ne bis in idem-gedachte waar het ging om de beoordeling van de toelaatbaarheid van allerhande combinaties van strafrechtelijke en bestuursrechtelijke sanctionering anders dan door middel van een bestuurlijke boete. Tegelijkertijd maakte de Hoge Raad in zijn uitspraak al direct duidelijk dat men voorzichtig moest zijn met het extrapoleren van het oordeel van de Hoge Raad naar andersoortige situaties door te overwegen dat zich in casu 'een uitzonderlijke - van andere gevallen waarin een bestuursrechtelijk en een strafrechtelijk traject samenlopen, afwijkende - situatie voordoet die op gespannen voet staat met het, aan art. $68 \mathrm{Sr}$ ten grondslag liggende, beginsel dat iemand niet tweemaal kan worden vervolgd en bestraft voor het begaan van hetzelfde feit'. ${ }^{7}$ Zoals in de volgende paragraaf nader wordt toegelicht, moet deze formulering achteraf bezien als een serieus te nemen waarschuwing worden beschouwd.

\section{De ontwikkelingen van het ne bis in idem-beginsel nadien $^{8}$}

Drie jaar en de nodige arresten later kan worden vastgesteld dat het Alcoholslotprogramma-arrest inderdaad eerst en vooral betekenis voor de specifiek in die zaak aan de orde zijnde problematiek van het alcoholslotprogramma lijkt te hebben gehad. Nadien is in de jurisprudentie in gevallen van samenloop van strafrechtelijke en bestuursrechtelijke maatregelen geregeld betoogd dat zich een met het alcoholslotprogramma vergelijkbare situatie voordeed, maar steevast zonder succes. In die zin kan achteraf worden vastgesteld dat dit arrest - hoewel ne bis in idem interessant genoeg tot de beginselen van een goede procesorde werd gerekend - geen ingrijpende koerswijziging inhield bij de beantwoording van de vraag onder welke omstandigheden cumulatie van strafrechtelijke en bestuursrechtelijke procedures al dan niet mogelijk is. In ieder geval heeft de Hoge Raad - wellicht anders dan in sommige gevallen mocht worden verwacht - nadien verschillende gevallen van sanctiecu-

\footnotetext{
Zie HR 3 maart 2015, NJ 2015/256, r.o. 4.3.2.

8. De inhoud van deze paragraaf is voor een belangrijk deel ontleend aan Crijns \& Van Emmerik 2018, waar de beschreven ontwikkelingen in de jurisprudentie uitgebreider worden besproken. 
mulatie gefiatteerd, ofwel door te oordelen dat geen sprake was van bestraffing voor hetzelfde feit in de zin van artikel $68 \mathrm{Sr}$ omdat de juridische aard van de feiten in de beide onderscheiden procedures wezenlijk uiteenliep, ${ }^{9}$ ofwel door te oordelen dat geen sprake was van een combinatie van punitieve sancties waardoor van schending van het verbod van dubbele bestraffing geen sprake kan zijn. ${ }^{10}$ Ook overwoog de Hoge Raad een aantal maal expliciet dat in het onderhavige geval geen sprake was van een met het alcoholslotprogramma vergelijkbare situatie, daarmee het uitzonderlijke karakter van de in dat arrest aan de orde zijnde combinatie nog eens verder onderstrepend. ${ }^{11}$ De conclusie voor wat betreft de nationale jurisprudentie lijkt dan ook te moeten luiden dat - ondanks het verheffen van het verbod van dubbele bestraffing tot een van de beginselen van een goede procesorde - nog steeds betrekkelijk ruime mogelijkheden bestaan tot het cumuleren van strafrechtelijke en bestuursrechtelijke procedures. Bij die stand van zaken kan de vraag worden opgeworpen of het toekennen van het karakter van beginsel aan de ne bis in idem-gedachte uiteindelijk veel praktische betekenis heeft, althans voor zover het gaat om de samenloop van strafrechtelijke en bestuursrechtelijke procedures.

Ook op Europees niveau is er de afgelopen jaren interessante jurisprudentie gewezen op het gebied van ne bis in idem en samenloop, waarbij de tendens lijkt te zijn dat wat betreft samenloop van (punitieve) handhavingstrajecten meer mogelijk is dan voorheen het geval leek te zijn. Het Europees Hof voor de Rechten van de Mens (EHRM) nam in dit geval het voortouw met zijn uitspraak in de zaak A. en B. tegen Noorwegen eind 2016. ${ }^{12}$ In deze zaak ging het om de vraag of de combinatie van een bestuursrechtelijke en een strafrechtelijke bestraffende sanctie voor een en dezelfde gedraging - het nalaten verkoopwinst aan de fiscale autoriteiten op te geven - al dan niet in strijd was met het verbod van dubbele bestraffing zoals neergelegd in artikel 4 Zevende Protocol EVRM. Verrassend genoeg kon deze combinatie volgens het EHRM door de beugel. ${ }^{13}$ Voor deze conclusie acht het EHRM relevant dat beide procedures een voldoende nauwe samenhang hadden, zowel inhoudelijk als in tijd. Factoren die een rol spelen bij de vraag of van een dergelijke samenhang sprake is, zijn: a) of de verschillende procedures complementaire doelen dienen en aldus niet alleen in abstracto maar ook in concreto verschillende aspecten van hetzelfde 'sociale wangedrag'

9. Zie bijv. HR 29 februari 2016, NJ 2016/143 m.nt. Kooijmans, daarbij aansluitend bij het standaardarrest HR 1 februari 2011, NJ 2011/394 m.nt. Buruma.

10. Zie bijv. HR 14 februari 2017, NJ 2017/289 m.nt. Reijntjes over de combinatie van een strafvervolging met een zogenoemde randvoorwaardenkorting op GLB-inkomenssteun; HR 12 december 2017, NJ 2018/94 m.nt. Reijntjes over de combinatie van een strafvervolging en het verbeuren van een dwangsom; en HR 16 januari 2018, NJ 2018/64 met betrekking tot de combinatie van een strafvervolging en een zogenoemde Educatieve Maatregel Alcohol en Verkeer.

11. Zie bijv. HR 5 december 2017, ECLI:NL:HR:2017:3062 over de combinatie van een strafvervolging met een bestuursrechtelijk huisverbod.

12. Zie EHRM 15 november 2016, AB 2017/188 m.nt. Barkhuysen \& Van Emmerik ( $A$. en B. te Noorwegen).

13. Zie hierover onder meer P.J. Wattel, 'Bis in idem', NJB 2017/205. op het oog hebben; b) of de cumulatie van de procedures voor de overtreder voorzienbaar is; c) of de verschillende betrokken autoriteiten met elkaar samenwerken en/of overleg hebben, meer in het bijzonder ten aanzien van de bewijsgaring en het bewijsgebruik in beide procedures; en d) of het totaalpakket aan opgelegde sancties evenredig is, in die zin dat bij de oplegging van de tweede sanctie rekening kan worden gehouden met de (aard en hoogte) van de eerder opgelegde sanctie. Aldus formuleert het EHRM een aantal vrij strikte criteria, maar indien deze worden vervuld, behoort een combinatie van punitieve sancties in twee afzonderlijke procedures dus wel degelijk tot de mogelijkheden zonder daarmee in strijd te komen met artikel 4 Zevende Protocol EVRM. ${ }^{14}$ Uit de schaarse Straatsburgse jurisprudentie op dit punt tot op heden lijkt te kunnen worden afgeleid dat het EHRM de mogelijkheden tot samenloop van strafrechtelijke en punitief-bestuursrechtelijke procedures met name ziet op terreinen die tot de 'soft core criminal law' kunnen worden gerekend, zoals het belastingrecht en het verkeersrecht. ${ }^{15}$

De vraag was vervolgens of het Hof van Justitie van de EU de door Straatsburg ingezette lijn zou gaan volgen, temeer daar de advocaat-generaal van het Hof in zijn conclusie bij een viertal prejudiciële Italiaanse zaken het Hof van Justitie had geadviseerd dit vooral niet te doen, nu de door het EHRM ingezette koers volgens hem complex en weinig inzichtelijk was. ${ }^{16}$ Recent gaf het Hof van Justitie uitsluitsel in zijn uitspraken in deze vier Italiaanse zaken. ${ }^{17}$ Hierin benadrukt dit Hof weliswaar dat het zijn eigen afwegingen maakt en zich niet gebonden acht aan de uitleg die het EHRM aan artikel 4 Zevende Protocol geeft, maar kiest het vervolgens niettemin een richting die sterk vergelijkbaar is met de door het EHRM in A. en B. tegen Noorwegen ingezette koers, zij het in deels andere bewoordingen. Ook volgens het Hof van Justitie zijn er namelijk wel degelijk omstandigheden denkbaar waarin verschillende punitieve procedures met elkaar kunnen worden gecombineerd, zonder dat daarmee in strijd wordt gehandeld met het verbod van dubbele bestraffing zoals neergelegd in artikel 50 van het EU-Grondrechtenhandvest. Of beter gezegd: er zijn omstandigheden denkbaar waaronder een dergelijke strijd met het verbod van dubbele bestraffing op grond van de algemene beperkingsbepaling van artikel 52 van het EU-Grondrechtenhandvest toch gerechtvaardigd kan zijn. Hierbij spelen volgens het Hof de volgende

14. In EHRM 18 mei 2017, NJB 2017/1649 (Jóhannesson e.a. t. IJsland) waarin ook sprake was van samenloop tussen een strafvervolging en een fiscale boete, oordeelde het EHRM dat art. 4 Zevende Protocol EVRM wel was geschonden, aangezien naar het oordeel van het EHRM niet kon worden gesproken van voldoende inhoudelijke en temporele samenhang tussen beide procedures.

15. Zie nader Crijns \& Van Emmerik 2018, p. 1100, met verwijzing naar EHRM 23 november 2006, AB 2007/51 m.nt. Barkhuysen en Van Emmerik (Jussila t. Finland)

16. Zie bijv. conclusie A-G Campos Sánchez-Bordona van 12 september 2017, ECLI:EU:C:2017:667 (Menci).

17. Zie HvJ EU 20 maart 2018, C-524/15 (Menci; ECLI:EU:C:2018:197), C-537/16 (Garlsson Real Estate SA e.a.; ECLI:EU:C:2018:193), gevoegde zaken C-596/16 en C-597/16 (Di Puma en Zecco; ECLI:EU:C: 2018:192). 
factoren een rol: a) het dient te gaan om een belangrijk doel van algemeen belang, waarbij de strafrechtelijke vervolging en de punitief-bestuurlijke procedure complementaire doelen dienen te hebben; b) de betreffende wettelijke regeling moet duidelijk en nauwkeurig zijn, zodat een eventuele cumulatie voorzienbaar is voor betrokkene; c) er moeten regels zijn die zorgdragen voor onderlinge afstemming tussen de verschillende betrokken handhavingsautoriteiten, zodat de extra belasting die voor de betrokkene uit de cumulatie voortvloeit, tot het strikt noodzakelijke wordt beperkt; en d) er moeten regels zijn die voorzien in de evenredigheid van het totale sanctiepakket. Aangezien het een prejudiciële procedure betrof, is het nu aan de Italiaanse rechter om te bepalen of in de betreffende zaken al dan niet aan deze voorwaarden is voldaan.

Wat daar verder van zij, evenals het Straatsburgse Hof lijkt het Hof van Justitie onder bepaalde (strikte) omstandigheden cumulatie van punitieve sancties toelaatbaar te achten. Tegelijkertijd moet ervoor worden gewaakt al te verstrekkende conclusies te verbinden aan de tot op heden beschikbare Straatsburgse en Luxemburgse jurisprudentie op dit punt, nu nog bepaald onhelder is in welke richting deze zich verder zal uitkristalliseren. Zo kan ten aanzien van het Luxemburgse kader bijvoorbeeld de vraag worden gesteld wat in dit verband precies moet worden verstaan onder 'regels' die moeten zorgen voor onderlinge afstemming waardoor de ongewenste gevolgen van de cumulatie kunnen worden geminimaliseerd. Ook de vraag naar de noodzakelijke complementariteit in doelstellingen van beide procedures - hetgeen zowel in het Straatsburgse als het Luxemburgse kader een relevante factor is - zal in de praktijk ongetwijfeld nog voor de nodige hoofdbrekens gaan zorgen.

\section{4. (On)wenselijkheid van sanctiecumulatie}

Op basis van het voorgaande kan voorzichtig worden vastgesteld dat de mogelijkheden tot samenloop van strafrechtelijke en punitief-bestuursrechtelijke sancties eerder groter dan kleiner lijken te worden. De vraag is wat de consequenties van deze trend zouden kunnen of moeten zijn. Vanuit het perspectief van individuele rechtsbescherming voor de burger die aan dergelijke dubbele handhavingstrajecten wordt onderworpen, lijkt dit niet direct goed nieuws. Tegelijkertijd passen hier de nodige relativeringen. Ten eerste zijn de voorwaarden voor toelaatbare samenloop van punitieve sancties blijkens de besproken Europese jurisprudentie tamelijk streng (al zal de toekomst moeten uitwijzen hoe strikt deze in de praktijk zullen worden geïnterpreteerd). Ten tweede kent de Nederlandse wetgeving nog een aantal duidelijke grenzen die ongewenste cumulatie van bestuursrechtelijke en strafrechtelijke sanctionering in tamelijk absolute termen verhinderen, althans indien en voor zover het gaat om de combinatie van een strafvervolging met een bestuurlijke boete (vgl. artikel 243 lid 2 Sv en artikel 5:44 Awb), ${ }^{18}$ zelfs wanneer deze binnen de grenzen van de recente Europese jurisprudentie eventueel nog toelaatbaar zou kunnen zijn. Deze Nederlandse grenzen zijn zodanig dat de verschillende vormen van cumulatie zoals die zich voordeden in de hiervoor besproken Straatsburgse en Luxemburgse zaken naar Nederlands recht vermoedelijk niet mogelijk zouden zijn. Dit alles neemt niet weg dat blijkens de hiervoor kort besproken nationale jurisprudentie ook binnen de Nederlandse verhoudingen samenloop van punitieve procedures binnen zekere voorwaarden wel degelijk tot de mogelijkheden behoort, zij het langs iets andere weg, namelijk door niet al te snel aan te nemen dat een feitelijke gedraging ook juridisch bezien hetzelfde feit oplevert. ${ }^{19}$ Ook hebben we in het voorgaande gezien dat de Hoge Raad bepaalde combinaties fiatteert door het vermeende punitieve karakter aan de betrokken bestuursrechtelijke sanctie te ontzeggen, als gevolg waarvan strikt genomen geen sprake is van een combinatie van punitieve trajecten maar waarin niettemin een voor de direct betrokkene ingrijpende combinatie van sancties aan de orde kan zijn. Dit alles doet onder meer de vraag rijzen wat nu precies het karakter is van het verbod van dubbele bestraffing: is het inderdaad een beginsel, zoals de Hoge Raad in het Alcoholslotprogramma-arrest stel$\mathrm{de}$, of is het veeleer een regel waarop afhankelijk van de aan de orde zijnde context naar goeddunken uitzonderingen kunnen worden gemaakt? Voorts rijst de meer praktische vraag hoe de betrokken handhavingsautoriteiten - het Openbaar Ministerie en een bestuursorgaan (en in voorkomende gevallen de later oordelende rechter) - hiermee dienen om te gaan. Eerder betoogden wij dat dit in ieder geval betekent dat alle betrokkenen de evenredigheid van het totale sanctiepakket actief in het oog dienen te houden en zich in hun oordeelsvorming aldus niet mogen beperken tot hetgeen binnen de eigen procedure 'aan de orde is'. ${ }^{20}$

Voorts dringt de vraag zich op welk doel precies wordt gediend met het realiseren van een dergelijke samenloop van punitieve procedures. Of zoals in de inleiding al anders geformuleerd: is een dergelijke cumulatie van sancties niet wat te veel van het goede? Met het opwerpen van deze vraag verlaten we de min of meer vaste grond van de rechtmatigheid en betreden we het zachtere terrein van opportuniteit en doelmatigheid. Vermoedelijk betekent dit dat het antwoord op deze vraag evenmin al te vastomlijnd kan zijn. Niettemin menen wij dat de in het voorgaande beschreven ontwikkelingen voldoende aanleiding geven tot het opwerpen van deze vraag. Het feit dat het cumuleren van handhavingstrajecten juridisch mag, betekent immers nog niet dat

18. Zie voor de vraag hoe deze bepalingen precies in samenhang met elkaar dienen te worden gelezen, mede gelet op de volgordelijkheid van de verschillende proceshandelingen, HR 6 oktober 2015, NJ 2016/130 m.nt. Reijntjes.

19. Vgl. het eerdergenoemde arrest HR 9 februari 2016, NJ 2016/143 m.nt. Kooijmans.

20. Zie Crijns \& Van Emmerik 2018. 
dit ook zou moeten of dat dit verstandig, opportuun of doelmatig zou zijn. Daarbij moet worden bedacht dat de vraag of al dan niet tot handhaving wordt overgegaan in het strafrecht wordt beheerst door het opportuniteitsbeginsel (artikelen 167 en $242 \mathrm{~Sv}$ ), terwijl in de context van het bestuursrecht de beginselplicht tot handhaving uitsluitend een rol speelt in geval van reparatoire sancties. ${ }^{21}$ In zoverre wordt een eventuele cumulatie van strafrechtelijke en punitief-bestuurlijke sancties in volle omvang beheerst door het opportuniteitsbeginsel of daarmee te vergelijken 'vrije' overwegingen en is er - anders dan eventueel eerder vastgesteld handhavingsbeleid - dus weinig tot niets dat tot het bewerkstelligen van een dergelijke cumulatie van sancties zou dwingen. Daar komt bij dat de meeste handhavingsautoriteiten doorgaans in meer of mindere mate hebben te kampen met een tekort aan capaciteit, wat temeer de vraag doet rijzen waarom een en dezelfde gedraging dan binnen meerdere punitieve handhavingstrajecten op de korrel zou moeten worden genomen. Daarmee is niet gezegd dat een combinatie van punitieve sancties onder omstandigheden geen redelijk doel zou kunnen dienen, maar minst genomen mag worden verwacht dat de verschillende betrokken instanties expliciet nagaan of een dergelijk redelijk doel ook daadwerkelijk aanwezig is. Op basis van het verleden - bijvoorbeeld in relatie tot de gang van zaken ten aanzien van het alcoholslotprogramma - kan er niet zonder meer op worden vertrouwd dat een dergelijke afweging in de praktijk ook daadwerkelijk altijd wordt gemaakt.

De opgeworpen vraag kan voorts ook abstracter worden opgevat, in die zin dat de beschreven ontwikkelingen de vraag oproepen waarom de wetgever dergelijke mogelijkheden tot cumulatie faciliteert. Enerzijds kunnen de beschreven ontwikkelingen op Europees niveau worden beschouwd als een duwtje in de rug voor het fenomeen van sanctiecumulatie, nu het - zeker bij een eventuele aanpassing of slechting van de ter zake geldende Nederlandse grenzen - niet alleen duale handhaving in abstracto maar onder omstandigheden ook in concreto mogelijk maakt. Anderzijds kan worden betoogd dat juist het ontstaan van deze mogelijkheid dermate indruist tegen hetgeen wij binnen de Nederlandse context nog vinden stroken met het verbod van dubbele bestraffing - daarbij uitgaande van de door de Hoge Raad geformuleerde gedachte dat dit verbod zodanig fundamenteel is dat dit tot een van de beginselen van een goede procesorde moet worden gerekend - dat dit noopt tot het maken van helderder keuzes op het niveau van de wetgever. Daar waar de wetgever de mogelijkheden in abstracto niet schept, kunnen zij in concreto immers ook niet bestaan. In die zin zouden de beschreven ontwikkelingen ook de wetgever aan het denken kunnen zetten over de vraag of en in hoeverre we cumulatie van punitieve procedures in de toekomst oppor-

21. Zie over de beginselplicht onder meer ABRvS 5 oktober 2011, $A B$ 2011/307 m.nt. Vermeer en ABRvS 4 juni 2014, AB 2014/451 m.nt. Vermeer. tuun achten en wat dit betekent voor de keuze tussen strafrechtelijke en/of bestuursrechtelijke handhaving. ${ }^{22}$ deze bijdrage verschenen Nader rapport bij het ongevraagd advies van de Afdeling advisering van de Raad van State over de verhouding tussen de sanctiestelsels in het bestuursrecht en het strafrecht (advies van 13 juli 2015, No. W03.15.0138/II, Stcrt. 2015, 30280) houdt het kabinet vast aan de mogelijkheid van het bestaan van duale stelsels, maar benadrukt het dat in dergelijke stelsels (bestaande dan wel toekomstige) het Openbaar Ministerie en bestuursorganen hun requireer-, respectievelijk boetebeleid onderling op elkaar dienen af te stemmen. Zie Kamerstukken II 2017/18, 34775 VI, 102 (bijlage). 